\title{
Subversión e intertextualidad en la saga Shrek
}

Recibido: noviembre 2011

\author{
Xavier MíNGUEZ LÓPEZ \\ Universitat de València \\ Grupo ELCIS ${ }^{1}$ \\ Xavier.minguez@uv.es
}

Aceptado: marzo 2012

\section{RESUMEN}

El estudio de los dibujos animados parece cada vez más importante para determinar la construcción de la competencia literaria de niños y jóvenes. En el caso que nos ocupa vemos como la saga de las películas de Shrek contiene una gran cantidad de alusiones literarias, tanto relacionadas con las fuentes folklóricas, como con otras fuentes más actuales. La combinación de las referencias, junto con el juego de tipo literario que se ofrece, sobre todo a través de la intertextualidad, convierte a Shrek en una obra de obligada referencia.

Palabras clave: Intertextualidad, dibujos animados, literatura de tradición oral

\section{RÉSUMÉ}

\section{Subversion et intertextualité dans la saga Shrek}

L'analyse de la bande dessinée semble être de plus en plus importante dans la détermination de la construction de la compétence littéraire des enfants et des jeunes. Dans le cas présent, nous voyons comment la saga des films Shrek contient une foule d'allusions littéraires, liées à des sources folkloriques, ainsi qu'à d'autres sources plus actuelles. La combinaison de références, et le jeu de type littéraire qui est proposé, notamment à travers l'intertextualité, font de Shrek un ouvrage de référence obligatoire.

Mots-clé : Intertextualité, dessins animés, littérature folklorique.

\section{ABSTRACT}

\section{Subversion and intertextuality in the Shrek saga}

The study of the cartoon seems to be increasingly important in determining the construction of literary competence of children and youth. In the present case, we see how the saga of the Shrek films contains a wealth of literary allusions, both related to folk sources, as with other current sources. The combination of references, along with the literary game that is offered, especially through intertextuality, makes Shrek an obligatory reference work.

Key words: Intertextuality, Cartoons, Folktales.

${ }^{1}$ Este artículo se enmarca en el proyecto de I+D "Educación literaria e interculturalidad" (EDU2008-01782/EDUC) financiado por el Ministerio de Ciencia e Innovación 
SUMARIO: 1. Introducción 2. Relaciones transtextuales en Shrek 3.La subversión 4. Conclusiones: la intertextualidad y la construcción de la competencia literaria.

\section{INTRODUCCIÓN}

La aparición de la película Shrek (Andrew Adamson y Vicky Jenson 2001) en el panorama de la filmografía para niños y jóvenes marcó posiblemente un hito que supuso la ruptura de muchas normas escritas y no escritas de este género. Tras una década de películas, merchandising, pero también de numerosos artículos académicos sobre el fenómeno, creemos interesante recuperar y revisar a la luz de lo dicho nuestra aportación (Mínguez et alii 2004). Shrek ha merecido un trato desde la posmodernidad (Cano 2003), la sicología (Sari 2009, Thompson 2005), la ecología (Caputi 2007), la discriminación racial (Babham: 2006, Pimentel \& Velázquez: 2009), la educación audiovisual (Gámez 2007, Ros 2007) y muchos otros puntos de vista.

En este artículo trataremos de analizar los diferentes juegos transtextuales que podemos ver en la saga de Shrek, junto con su componente subversivo que tiene mucho de juego literario. Así mismo trataremos de ligar este recurso recurrente en las películas con la construcción de la competencia literaria por parte de los niños y niñas del SXXI.

Para el concepto de intertextualidad se puede consultar el dialogismo de Bajtin (Bajtin 91, 93), y los trabajos de Kristeva (1978), Barthes (1968), Genette (1989) y especialmente Rifatterre (1978) y Mendoza (2001) quien habla del intertexto como un elemento fundamental en la construcción de la competencia literaria. Lluch (1998) aplica el esquema de relaciones transtextuales de Genette a la narrativa infantil y juvenil dando lugar a diversas reflexiones sobre la misma que podemos aplicar sin fisuras en nuestro estudio. Lluch destaca la transformación satírica que da lugar al travestismo burlesco tan productivo dentro de la LIJ de nuestro siglo, en especial a partir de la obra de Gianni Rodari Gramática de la fantasía (1986). Los procesos de transformar, imitar, satirizar y jugar a los que aludía se repiten hasta la saciedad en las obras estudiadas.

Es también necesario detenerse en otro apartado como es la relación de los dibujos animados con los relatos de base folklórica ya que, desde el inicio de la animación, estos relatos han sido una fuente de inspiración imprescindible para los artistas. Las adaptaciones de los clásicos recopilados por Perrault o los hermanos Grimm han sido llevadas a la pantalla en innumerables ocasiones, y siempre con la visión reduccionista de la que habla Lluch tanto en el trabajo citado como en su trabajo sobre las transformaciones que sufren los relatos orales al convertirse en literatura infantil (Lluch 2000).

Sin duda el mayor exponente de esta visión es Walt Disney cuya influencia ha sido tanta en el mundo occidental que se habla de sus películas como configuradoras del imaginario colectivo (Lluch y Jutge 2002). Es sencillo constatar que tanto las versiones de los diferentes cuentos tradicionales, como la misma 
imagen de los personajes con las que se identifica la inmensa mayoría de los individuos de las sociedades occidentales son deudoras de este artista. De hecho, resulta difícil rescatar las versiones nacionales de cuentos como La Cenicienta o Blancanieves sin que aparezcan recurrentemente las modificaciones que realizó la factoría Disney sobre ellas. Según Lluch (1998) todos los productos cinematográficos tienen las mismas características: fluidez narrativa, imágenes endulzadas y rechazo de las escenas consideradas "fuertes" del hipotexto, así como el uso constante de una moral que cierra la historia. Las versiones de Disney han sido muy contestadas. Por citar dos críticas clásicas nombraremos a Sayers (1965) y Mattelart (1972), pero también McQuillan y Byrne (2000).

Respecto del contexto en el que se produce Shrek hay que recordar que la productora Dreamworks se embarcó en la aventura de este film de animación con un propósito claro: romper el monopolio del film de animación en manos, precisamente, de la factoría Disney (Gámez 2007: p.7, Márquez 2003: p. 281-282), cosa que explicará numerosas intertextualidades.

\section{RELACIONES TRANSTEXTUALES EN SHREK}

Las relaciones transtextuales en Shrek son numerosas y toman como base diversos referentes. Veámoslo con detenimiento:

\subsection{Los relatos de base folklórica, relatos populares y cuentos de autor}

Esta es la fuente de buena parte de sus hipertextualidades. Probablemente el componente más destacado de esta hipertextualidad es el mismo inicio: un cuento de hadas narrado por una voz en off. Inicio que, en diferente formato, se repetirá en todas las entregas. El mismo protagonista es un ogro, antagonista de infinidad de relatos tradicionales de los que toma algunas de sus características que en el film se concretan en su descripción, aunque ésta esté basada en la obra de Steig (1990). La primera escena de Shrek, de hecho, se trata de la presentación de este personaje con un contenido altamente escatológico (su primera aparición la hace saliendo del wáter con el ruido de la cadena de fondo). Shrek se lava en lodo, pesca con sus poderosas ventosidades y come toda clase de insectos babosos. Se elimina la tradicional referencia a su apetito de carne humana, una constante en el cuento tradicional, para ahondar en su carácter bondadoso. La coprotagonista, la princesa Fiona, tampoco sale de ningún cuento en concreto sino de miles de cuentos en los cuales una princesa espera el rescate por parte de su príncipe. Esta característica del cuento tradicional se mezcla con otro clásico como es el encantamiento malintencionado por parte de una bruja poco después de su nacimiento. En este caso el encantamiento la convierte en mitad princesa mitad ogresa.

Junto con Shrek y Fiona, otros personajes secundarios comparten con ellos la falta de ubicación en un cuento recopilado por un autor de prestigio. Es el caso del asno parlante (¿tal vez el asno de Apuleyo? [Caputi 2007:3]), del Hada Madrina o del mismo Príncipe Encantador, estos dos últimos pertenecientes a la galería de 
personajes del mundo de los cuentos sin ubicación precisa, como los duendes, magos, elfos, etc. que aparecen en todas las entregas. En algunos casos, hay una relectura del papel de estos personajes en el universo fantástico como es el caso del Hada Madrina que aparece como una mezcla entre empresaria bioquímica y alcahueta o el Gato con botas, un asesino a sueldo...de ogros. Rumpeltiskin aparece convertido en un estafador que busca convertirse en el rey de Muy, Muy Lejano gracias a una triquiñuela que hará desaparecer a Shrek del mapa. El flautista de Hammelin será un cazador de recompensas. También muchos otros personajes se reinterpretan, como los gigantes que ejercen de matones, las hadas que sirven de fanales en la noche, el espejo mágico que actúa de televisión, etc.

No solo se encuentran intertextualidades con las narraciones sino con todo el mundo que rodea la producción, como es la misma alusión a los autores. En la segunda entrega, en un momento de rabia, el hada madrina grita "¡Por el amor de los Grimm!”; en la tercera, Arturo también dice “¡Por Christian Andersen!”. Esta curiosa referencia resulta casi imposible de explicar sin romper con un esquema tras otro (o sin jugar a las matrioshkas). ¿Cómo es posible que los personajes conozcan a sus autores? ¿Qué papel harían los escritores en un mundo con sus personajes? Estos son guiños que se deben explicar desde el mundo ficcional, obviamente. Es un metalenguaje dirigido al espectador y desvinculado del pacto de ficción básico que se realiza al inicio de las obras.

Pero sin duda, el aspecto que más llama la atención por su poderoso efecto hipertextual, tiene como hipotextos los cuentos más popularizados por los recopiladores del XIX. Básicamente, porque basta con una pequeña referencia para desatar las conexiones intertextuales a las que aludían los deconstructivistas. Aquí se presenta a la Cenicienta y Blancanieves como solteras a la espera de encontrar un príncipe que se decida a rescatarlas. En la tercera entrega estas princesas parecen continuar solteras a pesar de hacer referencias al cuento de donde provienen. Los tres cerditos, con acento alemán, son expulsados del bosque de Lord Farquaad junto con su peor enemigo, el lobo, quien comparte protagonismo en dos cuentos: Los tres cerditos y Caperucita Roja, ya que aparece vestido con un pijama de abuela. Los autores convierten a estos y otros personajes en asiduos de la serie con un papel que parte de su personaje tradicional (desprovisto de rasgos sicológicos) pero revestido de personalidad propia como es natural en una obra más extensa (Millán 2003).

\subsection{Los clásicos de autor}

En el caso de los clásicos de autor incluimos aquí básicamente personajes de dos de las novelas para niños más importantes como son Pinocho, del SXIX, y Peter Pan, siglo XX. La alusión a Alicia en el país de las maravillas se reduce al "Cómeme" de Gingerbread a Lord Farquaad. También el protagonista del ciclo artúrico, ciclo a caballo entre la tradición oral, el folklore y las diferentes obras de autor que las han popularizado, el mismo Arturo aparece en el Capitulo final. Peter 
Pan tiene un papel claramente de comparsa en las tres primeras entregas, pero Pinocho (a pesar de provenir de la tradición mediterránea) adquiere un gran protagonismo a partir de la segunda parte al hacerse amigo de Shrek en la primera. De Pinocho, se hace uso de la característica que en el libro original tan solo ocupa un aspecto anecdótico como es su problema con la nariz y las mentiras. Pero también se hace referencia a su conflicto de doble personalidad niño/muñeco y su carácter de marioneta. En Shrek Tercero incluso aparece el Comefuegos como un antagonista que se une a la revuelta del príncipe encantador.

Respecto de Arturo, su carácter adolescente le confiere un valor añadido a su aparición en escena. Deja de interpretar al héroe que acostumbra a ser en los relatos artúricos y se presenta como un adolescente desgraciado y acosado por sus compañeros. El mago Merlín, convertido en una especie de gurú de la New Age, ejerce de consejero parodiando todos los tópicos habituales de estos particulares personajes: el uso de un vocabulario específico, la música, etc. Las necesidades del guión hace presentar a Lanzarote como un caballero mayor o al menos coetáneo de Arturo de la misma manera que Ginebra (al revés que en las fuentes originales), ambos unos pijos insufribles. Estos cambios físicos de algunos personajes que cobran importancia en otros capítulos de la saga se dan también en el caso de las princesas, Rumpeltiskin o el flautista de Hamelin.

\subsection{Las Nursery Rhymes y otras canciones populares}

Las Nursery Rhymes, de amplia difusión en todo el ámbito anglosajón, sirven a los creadores de Shrek para incluir dos personajes que acabarán formando parte de la troupe que acompaña al protagonista. Se trata del hombre de pasta de jengibre y los tres ratones ciegos. Ambos pertenecen a sendas poesías populares. En el caso del hombre de pasta de jengibre (Gingerbread man), la poesía sirve de hipotexto para la aparición del muñequito, en un principio, en una sala de tortura (sobre una bandeja de hornear pan, como en la rima), pero también para una de las intertextualidades más crueles de la película. Lord Farquaad se acerca al muñequito en pleno proceso de tortura y se burla descaradamente de él repitiendo los conocidos versos del estribillo mientras juega con sus piernas rotas. "Run, run as fast as you can /You can't catch me, I'm the gingerbread man"

Pero aquí no acaba el juego de intertextualidades de la escena ya que acto seguido Lord Farquaad pregunta dónde se encuentra el resto de criaturas fantásticas y el muñequito le responde con el inicio de una canción scout, que Lord Farquaad continúa como si fuera parte del diálogo. Así, la canción que dice: "Do you know the muffin man?/The muffin man, the muffin man/Who lives in Drury Lane?".

Se convierte en el diálogo:

Lord Farquaad: Where they are?

Gingerbread man: Do you know the muffin man?

Lord Farquaad: The muffin man?

Gingerbread man: Yes, the muffin man 


\section{Lord Farquaad: Who lives in Drury Lane?}

También los tres ratones ciegos (con gafas oscuras y bastón) que aparecen en todas las entregas de la saga, pertenecen a una conocida nursery rhyme. Nada más aparecer en la casa de Shrek, mientras el ogro se prepara para cenar, los ratones hacen referencia a su granja, por si el espectador no ha localizado el hipotexto. Permítannos detenernos aquí en las implicaciones interculturales que suponen estas tres referencias a un aspecto tan concreto como las Nursery Rhymes. Es obvio que, por mucha competencia literaria que tenga un niño o una niña fuera del ámbito anglosajón, es altamente improbable que conozca estos personajes. Las traducciones española y catalana del fragmento de The muffin man, son francamente ingeniosas y reproducen perfectamente el espíritu de la escena original. En español The muffin man pasa a ser Mambrú (que se fue a la guerra) y en catalán John Brown (que era un petit indi). Pero en el caso de los mismos personajes, el proceso descodificador del lector modelo ha de ser otro. Además, no todas las traducciones han sido tan ingeniosas ni fieles al texto original.

\subsection{Películas de acción, videojuegos y el metalenguaje de la animación}

Son estos otros hipotextos fundamentales para las películas de Shrek. De hecho, según Cano (2003:3), en Shrek parte de su contenido se establece a través de los resortes audiovisuales: rompiendo el mecanismo de percepción de lo real y con las referencias que comentaremos a continuación. Es muy sencillo descubrir estas hipertextualidades a lo largo de los filmes. Algunas de las escenas emblemáticas de la primera y segunda entrega, que se utilizaron en los diferentes anuncios publicitarios, hacen referencia a esta hipertextualidad. Una de las más llamativas es sin duda, la pelea protagonizada por la princesa Fiona contra los Hombres felices que pone punto y final a una canción del tipo de las que usa y abusa Disney en sus películas aunque con una letra bastante más irónica. Aquí las referencias a las películas de artes marciales son más que evidentes y es fácil ver al actor Jackie Chan en algunas de las técnicas utilizadas por la princesa. También hay una referencia a la entonces recién estrenada Tigre y dragón (Ang Lee 2000) en una de las acrobacias. Pero en esta escena la referencia que más divertida resulta por su radical anacronismo es la recreación del movimiento de cámara de The Matrix (Larry and Andy Wachowski 1999).

Otra de las hipertextualidades más llamativas y que, como la escena de lucha, también se utilizó en la publicidad, es el rescate de los protagonistas de Shrek 2 prisioneros en unas mazmorras. Aquí vemos a Pinocho lanzándose con sus hilos de marioneta al vacío tras hacer explotar la reja superior. Esta hipertextualidad viene reforzada con la música del hipotexto original, Misión imposible (Brian de Palma 1996), con lo cual la lectura es mucho más sencilla y evidente, cosa que no le quita humor a la escena, aun más, creemos que aumenta dicho efecto.

Las hipertextualidades continúan. La escena del casamiento de Shrek y Fiona constituye una referencia muy explícita a la también recién estrenada El señor de 
los anillos (Peter Jackson 2001) de donde se toma el mismo anillo forjado por enanos que con el calor refleja la inscripción I love you y que cae de las alturas directamente al dedo de Fiona, tal cual una conocida escena de la película mencionada. Las princesas que deciden pasar a la acción en Shrek Tercero, lo hacen creando una imagen fija deudora de la serie de acción Power Rangers. En Shrek, Capitulo final, vemos, entre otros efectos, el campamento de la resistencia de los ogros que puede relacionarse con innumerables filmes, desde las ambientadas en la $\mathrm{II}^{\mathrm{a}}$ Guerra Mundial y la resistencia francesa, hasta las de Ciencia-Ficción con enemigos diversos: extraterrestres, zombies, bandas rivales, etc.

La ruptura de percepción de lo real es un mecanismo muy utilizado en los dibujos animados desde los inicios de la Warner (Gámez 2007:12). Shrek aparta la cámara cuando va a besar a su esposa, la cámara sigue a Asno en su huída de los soldados como en la escena homóloga de El retorno del Jedi (Richard Marquand 1983), las escenas se ralentizan en muchos momentos de toda la saga: la huída ante el dragón, la sacudida de pelo del Príncipe Encantador, el baile de los ogros, etc. etc.. Los juegos con la cámara recuerdan al espectador que está ante una construcción ficcional.

\subsection{Referentes de la sociedad norteamericana}

Esta última hipertextualidad no cuenta con un referente concreto sino diversos hipotextos que se han configurado con el paso del tiempo y su aparición recurrente en numerosos filmes y teleseries. Se trata de escenas como el hilarante combate de pressing catch que lleva a cabo Shrek en el castillo de Lord Farquaad, escena en la cual no falta ninguno de los tópicos de estas espectaculares peleas como la espectadora que pide a gritos que se golpee al caído con la silla, la ayuda externa del ring (en este caso de asno), las diferentes acrobacias que son habituales en estos combates o los gestos del ogro imitando al popular luchador Hulk Hoogan.

También se ve una clara referencia a los restaurantes de comida rápida en la escena en que el Hada Madrina renuncia a su dieta y pide un par de menús. Como en otros casos se busca el humor con la transposición del referente real al hipotético restaurante del mundo de las hadas. Un ejemplo es el típico regalo de algunos menús de dichos restaurantes que en el menú medieval de Shrek 2 se convierte en una enorme hacha.

En la tercera entrega, el ambiente de instituto en el que vive Arturo, se nutre de las teleseries y películas que recrean de manera estereotipada el modo de vida adolescente. Así, Arturo será el joven incomprendido y víctima de acoso generalizado que verá una oportunidad de convertirse en "popular" gracias a la intervención del ogro. La escena incluye muchos otros tópicos como el hecho de presentar a los adolescentes con una edad aparente mayor a la que les corresponde, las drogas, el baile de fin de curso, las chicas pijas, las animadoras, etc.

Como en cualquier texto producido en cualquier cultura, las referencias culturales son innumerables y en algunos casos indescifrables para el espectador. 
Hemos hablado ya de las Nursery Rhymes y también de estos últimos ejemplos ligados a la cultura audiovisual, pero también deberíamos comentar detalles como el acento escocés del ogro, las referencias a sus orígenes europeos, la adscripción de Asno a la cultura afroamericana, o la más fácilmente identificable para los espectadores hispanoparlantes del gato con acento español (Babham: 2006, Pimentel \& Velázquez: 2009). De hecho estos autores hablan de la intencionalidad racista de los autores ya que caen en los estereotipos más comunes atribuidos a estas comunidades en Estados Unidos. Este aspecto pasa más bien desapercibido en otros países donde los filmes de Shrek pasan por ser una llamada a la tolerancia (Mínguez et alii 2004, Ros 2007, Varjal 2010).

También incluiríamos dentro de este apartado la importancia de la banda sonora de todas las películas. En un claro intento de distanciamiento del modelo de animación de Disney, los productores de Shrek decidieron utilizar el rock y el pop antes que las baladas melosas con voces impostadas. Así la nómina de grupos y artistas es realmente impresionante: Led Zeppelin, Paul McCartney, Ramones, Duran Duran, Stevie Wonder y una larga lista. Además de la banda sonora propia de la película, orquestada al uso, estas canciones suelen crear un doble efecto en el espectador: por una parte suele reconocer el origen y le produce sorpresa escucharlas en un contexto tan poco apropiado, sobre todo en la primera película donde se jugó mucho con el elemento de la novedad; pero por otra, y muy ligado a la sociedad en la que se lleva a cabo los filmes, las letras de las canciones crean un efecto humorístico obvio. Cuando Shrek pelea con los caballeros en el torneo citado arriba, suena Bad reputation (Joan Jett and The Blackhearts), ante la muerte del rey en Shrek Tercero un coro de ranas canta el estribillo "Live and let die" (Paul McCartney and The Wings), etc.

Pero tal vez una de las intertextualidades musicales más sutiles que dan cuenta de la dificultad de descodificación de determinados códigos culturales nos la da la corta intervención de Asno cantándole a un Shrek, preocupado por su inminente paternidad, la canción Cradle cats and Silver Spoon, de Harry Chaplin. La canción habla de un niño cuyo padre siempre relega a más tarde los juegos con su hijo. A pesar de ello, el niño siempre dice "de mayor seré como él". La canción acaba y es el trozo que canta Asno en la popa del barco, con el padre ya mayor que solicita la presencia de su hijo quien le contesta: "Ahora no puedo, pero intentaré ir más tarde" y el padre reconoce: "Es como yo". En la canción se alude a dos canciones populares infantiles Man in the moon y Cats in the cradle. Así, el juego de referencias y la multiplicación ante los diversos espejos de la intertextualidad es enorme. Asno alude a la próxima paternidad de Shrek usando una canción folk que reivindica la paternidad responsable, pero que también usa elementos de la tradición folklórica de la que ellos mismos son parte. Y todo ello en apenas diez segundos de metraje. 


\section{LA SUBVERSIÓN}

Es este, sin duda, el componente que más interés suscita desde nuestro punto de vista y desde la perspectiva de la Literatura Infantil y Juvenil. Como dice Allison Lurie (1989) la LIJ siempre ha sido un espacio subversivo ya que "sus valores no son los tradicionalmente convencionales en el mundo del adulto" (pág.13). Con la subversión (trastornar, revolver, destruir, especialmente en lo moral, según la RAE) se burlan los controles morales de los adultos y se pone en evidencia lo ridículo de este sistema. "Hacen una llamada a ese niño imaginativo, interrogante y rebelde que todos llevamos dentro, renovando nuestra energía instintiva y actuando como una fuerza que nos impulsa al cambio" (pág. 13). En nuestra opinión, es este componente de las películas de Shrek el que hace que resulten más fructíferas desde el punto de vista creativo.

El elemento subversivo de los filmes de Shrek se vehicula a nuestro parecer, a través de diversos elementos:

\subsection{La escatología y la reescritura de los roles tradicionales}

La escatología aparece en todos estos filmes de manera recurrente. Hemos comentado anteriormente la presentación altamente escatológica del ogro en la primera secuencia y como pretende así marcar diferencias con sus predecesores en la animación, en particular con las historias dulcificadas de Disney. La alusión a lo grotesco (Fortunato 2010) es una forma de liberarnos de las tensiones impuestas por la moral colectiva. Su presencia en un film de animación crea un gran shock en el espectador que no está acostumbrado a este tipo de recursos tan poco correctos políticamente hablando. Con este rasgo, se incide en el carácter salvaje de Shrek que renuncia a todo para vivir en su pantano, toda una imagen de la individualidad posmoderna (Zipes 2010, Cano 2003).

Los personajes protagonistas son tipos "marginalizados" (Varjal 2010) que se encuentran bien posicionados en la sociedad. No aspiran a ser reyes ni príncipes, sino a ser felices en su condición de outsiders. Esta reescritura de los cuentos tradicionales se retuerce aun más con ogros buenos, príncipes malos, princesas rebeldes, galletas aventureras, etc.

\subsection{El mensaje sobre la belleza}

En una sociedad como la nuestra, absolutamente esclava de los patrones de belleza estándar, la afirmación (y reafirmación) sobre la importancia de la belleza interior resulta también muy transgresora en cuanto a la ruptura con los modelos tradicionales (Thompson 2005). Aún más, y como en tantas ocasiones, Shrek da una vuelta más a la broma ya que debemos recordar que el mundo de los cuentos tradicionales es un mundo altamente sexista donde la belleza siempre es premiada y la fealdad castigada. (Mas, Mínguez, Romero 1999). La segunda parte de la película aún ahonda más en este mensaje trasgresor, ya que propone nuevas formas de sexualidad a través del emparejamiento de una reina con una rana y de un asno 
con una dragona (con quien incluso tiene hijos) y cuestiona los cambios físicos incidiendo en la belleza anterior. De hecho, Fiona no volverá a mostrar su forma humana ni en la tercera ni en la cuarta parte de la saga.

\subsection{La reivindicación del papel activo de la mujer}

Aunque puede entrar en algunas contradicciones internas, lo cierto es que el mensaje final de la saga Shrek apuesta por un papel activo de la mujer. La evolución del personaje de Fiona es un claro exponente de ello ya que, a pesar de acabar siendo esposa y madre, no deja nunca de ser una mujer independiente capaz de luchar por lo que quiere. Y lo hace en la primera película deshaciéndose de los Merry Men a golpe de kung-fu; en la segunda noqueando al Príncipe Encantador o renunciando a sus privilegios de princesa por ir con el hombre que ama; en la tercera, salvando a Shrek de la muerte o en la cuarta salvándose a ella misma de la torre en el supuesto de que Shrek no hubiera acudido a rescatarla. Las mujeres en estos filmes adquieren un rol activo y encontramos numerosos ejemplos de los cuales los más significativos, además del papel de Fiona, serían el antagonismo del Hada Madrina o la patrulla de mujeres que acaban salvando al reino de Muy Muy Lejano. Estas, además, pasan de la inactividad de la que hablábamos anteriormente a una pequeña revolución que incluye su cambio de aspecto físico (rasgan la ropa o afilan el zapato de cristal) e incluso un pequeño guiño al feminismo tradicional con la quema del sujetador.

\subsection{Los comentarios desmitificadores}

Este recurso muy frecuente a lo largo de las cuatro historias ayuda a cambiar el punto de vista sobre los personajes de los cuentos tradicionales. Consideramos que el componente trasgresor se encuentra precisamente en promover la reflexión sobre estos personajes, en cuanto que habitualmente son un modelo transmisor de los roles tradicionales. Así, cuando Blancanieves aparece en casa de Shrek en su urna de cristal, éste protesta diciendo: "La muerta fuera de la mesa". También los comentarios del espejo mágico sobre la misma Blancanieves ("Aunque viva con siete hombres, no es una mujer fácil") o sobre Cenicienta ("Ha sufrido abusos psicológicos"), contribuyen a desmitificar la imagen de princesas perfectas que tienen en el imaginario colectivo. Esta desmitificación se complementa con la propia princesa Fiona y con el resto de apariciones de las dos princesas (peleándose por el ramo de la boda o bailando con un enano o con Pinocho). También referirse a Pinocho como "el muñeco poseído" resulta una ironización de su condición mágica. Y descubrir el nombre de "Mudito" (Dopey), el nombre de uno de los siete enanitos en la versión de Disney, tatuado en un corazón en el brazo de Blancanieves... no solo es subversivo sino casi casi perverso. 


\subsection{La desendulcificación}

Este término acuñado por los autores, que utilizaremos a falta de encontrar otra definición mejor, da cuenta de un recurso muy frecuente en todas las películas y que, nuevamente, consideramos que tiene como diana las películas de Disney. Se trata de la ruptura de un momento especialmente dulce, tierno o solemne a través de diferentes mecanismos. Se da en muchas ocasiones al inicio o durante un número musical, como es el caso de la primera vez que Asno trata de entonar una canción sobre la amistad, o cuando los Hombres felices presentan a Monsieur Hood con un gracioso número que canta sus virtudes, incluso cuando el Hada Madrina trata de venderle la felicidad a la princesa Fiona. Pero, sin duda, la utilización más efectiva desde el punto de vista de la ruptura del momento dulce, en tanto que usa la ironía para presentar las peculiaridades de la princesa Fiona, es la competición de canto entre la misma princesa y un pequeño pajarito que acaba con la explosión de este a causa de un tono excesivamente alto. En realidad, la princesa compite con el pajarito tan solo a fin de conseguir sus huevos para preparar un desayuno.

\section{CONCLUSIONES: LA INTERTEXTUALIDAD Y LA CONSTRUCCIÓN DE LA COMPETENCIA LITERARIA}

A modo de conclusión, quisiéramos detenernos brevemente en un aspecto que no se puede dejar de lado ante el éxito entre niños y niñas de estas magníficas películas. Como hemos podido comprobar, las numerosas intertextualidades que utiliza la saga para vehicular las historias crea una red intrincada de referencias que, en muchos casos, exceden lo que podríamos considerar que es su competencia literaria. Este aspecto es más palmario cuanto más pequeños son los espectadores. En nuestra opinión, y como ya apunta Mendoza (2001), la intertextualidad alimenta la competencia literaria y crea un efecto boomerang que aumenta la misma competencia e incluso el alcance de las lecturas de intertextualidades. Así, la competencia literaria se nutriría de manera primaria del consumo de los propios referentes (cuentos, películas, etc.), pero también de manera secundaria, de las mismas referencias en tres niveles diferentes:

- Cuando no existe conocimiento previo. En este caso una hipertextualidad ayuda a construir la imagen del referente. Por ejemplo, la aparición de los tres ratones ciegos o de Gingerbread no alude a ninguna historia conocida para el público no anglosajón, pero su inclusión en esta red de alusiones constantes a cuentos tradicionales, nos hace pensar que forma parte de este universo.

- Cuando existe algún conocimiento previo. En este caso la referencia lo que hace es reforzar los conocimientos sobre la historia a la que alude. Si por ejemplo un niño o niña tan sólo conoce de Pinocho la frase "Si dices mentiras te crecerá la nariz como a Pinocho", su visión en Shrek le ayudará a contextualizarlo dentro de los cuentos de tradición popular. Además, se da 
nueva información sobre su condición de niño-muñeco. En este supuesto, como en el anterior, la pregunta al adulto puede completar la información.

- Cuando existe un conocimiento previo profundo. Aquí es cuando la hipertextualidad se configura como un recurso potente de alusión a la enciclopedia del lector-espectador. Cuanto mejor sea el conocimiento del referente, mayor y más profunda será la lectura. Cuando a Pinocho se le pide que diga como mentira que lleva ropa interior femenina y esta mentira no causa el efecto deseado porque no es tal mentira, los espectadores más jóvenes reirán al ver a Pinocho con un tanga rosa de mujer. El adulto, probablemente, relacionará esta circunstancia con el fetichismo y otras perversiones sexuales, cosa que, tratándose de un muñeco que vive en la esquizofrenia de ser a veces niño, podemos pensar que aumentará el efecto humorístico que su interpretación lineal no puede concederle.

Así pues, concluiremos este trabajo incidiendo en la gran fuerza de las obras analizadas en la construcción de la competencia literaria tanto a través de la subversión como de la intertextualidad. Una construcción que no acaba aquí sino que continúa en la mente del espectador cuando recupera las imágenes.

\section{REFERENCIAS BIBLIOGRÁFICAS}

BAJTIN, M.M. (1991): Teoría y estética de la novela, Madrid, Taurus.

- (1993): Problemas de la poética de Dostoievski, Bogotá, FCE.

BARTHES, R. (1968): “La muerte del autor”, en El susurro del lenguaje, Paidós, Barcelona

BRABHAM, D. (2006): “Animated Blackness in Shrek” en Rocky Mountain Communication Review, 3:1, p. 64-71

CANO GÁMEZ, Á. P. (2003): "Metalenguaje y otredad: posmodernidad en Shrek". Revista Latina de Comunicación Social, 56. Recuperado el 13 de febrero de 2011 de: http://www.ull.es/publicaciones/latina/20035633cano .htm

CAPUTI, J. (2007) "Green Consciousness: Earth-Based Myth and Meaning in Shrek", en Ethics \& the Environment, Volume 12, Number 2, Autumn 2007, pp. 23-44

COLOMER, T.(1998), La formació del lector literari, Barcelona, Barcanova.

FORTUNATO, I. (2010): “A estética do grotesco na animação Shrek", Revista Eletrõnica do Programa de Pós-graduação da Faculdade Cásper Líbero, $\mathrm{N}^{\circ} 1$.

FURNISS, M. (1998): Art in Motion: Animation Aesthetics, Sidney, John Libbey.

GÁMEZ, M.J (2007) Guía para ver y analizar Shrek, Valencia, Nau Llibres.

GENETTE, G. (1989), Palimsestos: la literatura en segundo grado. Madrid, Taurus.

KRISTEVA, J. (1978), Semiótica, Madrid, Editorial Fundamentos. 
LINDWALL, T.R, MATTHEW, J. (1997): "Towards a post-modern animated discourse: Bakhtin, intertextuality and the cartoon carnival", en PILLING, J., $A$ reader in animation studies, John Libbey, Sydney.

LLUCH, G. (1998): El lector model en la narrativa per a infants $i$ joves, Barcelona, Valencia, Castelló de la Plana, Aldea Global.

- (ed.) (2000) De la narrativa oral a la literatura per infants, Alzira, Bromera.

LLUCH, G y JUTGE, M.(2002): "Walt Disney: el creador del nostre imaginari", Faristol, núm. 42, Barcelona.

LURIE, A. (1989) No se lo cuentes a los mayores, FGSR, Salamanca.

MÁRQUEZ, A. (2003): "Shrek: The Animated Fairytale Princess Re-invented" en Fifty Years of English Studies in Spain (1952-2002). Santiago de Compostela , Publicacións Universidade de Santiago de Compostela.

MAS, J.A., MÍNGUEZ, X., ROMERO, F. (1999) "Per a una lectura políticament correcta de les Rondalles Valencianes d'Enric Valor", Valoriana. Estudis sobre l'obra d'Enric Valor, Castelló, Universitat Jaume I.

MCQUILlAN, M., BYRNE, E. (2000): Deconstructing Disney. London, Pluto Press.

MENDOZA, A. (2001). El intertexto lector. El espacio de encuentro de las aportaciones del texto con las del lector. Cuenca, Universidad de Castilla-La Mancha.

MÍNGUEZ, X. et alii (2004) "Intertextualidad y juego literario en Shrek 1 y 2", Actas del VII Congreso Internacional de la Sociedad Española de Didáctica de la lengua y la literatura, SEDLL, La Habana.

MILLAN BARROSO, P. J.(2003 )"Shrek: reflexiones contadas sobre la ficción y la parodia", Cauce. Revista de filología y su didáctica, $n^{\circ}$ 26, Madrid, Centro Virtual Cervantes.

PIMENTEL, O., VELÁZQUEZ, P. (2009)" Shrek 2: An Appraisal of Mainstream Animation's Influence on Identity" en Journal of Latinos and Education, 8 (1), 5-21.

RIFATTERE, M. (1978), Semiotics of Poetry, Bloomington, Indiana University Press, págs. 164-5

- (1991): «Compulsory reader response: the intertextual drive», en WORTON, M. y STILL， J. (1991). Intertextuality: Theories and practices. New York, Manchester University Press. Pp 56-78.

RODARI, G. (1986) Gramàtica de la fantasia. Barcelona, Aliorna

ROS, N. (2007) "El film Shrek: una posibilidad desde la educación artística para trabajar en la formación docente, la lectura de la identidad y los valores", Revista Iberoamericana de Educación, $\mathrm{n}^{\circ}$ 44/6.

SARI, O (2009) "Fairy Godmother Ambition Revealed In Shrek 2 Cartoon Movie: A Psychoanalytic Approach.", Skripsi Thesi, Universitas Muhammadiyah Surakarta. 
SAYERS, J (1965) “Walt Disney accused”, Horn Book Magazin, no 41, págs. 602611.

STEIG, W (1990) Shrek! , McMillan, New York.

THOMPSON, J.K. (2005) "Shrek, attractivism and appearance stereotypes: A make-ogre fairy tale, or happily ever after redux", PsycCRITIQUES, 50.3.

VARJAL, P.M. (2010) "Shrek e a dessacralização dos contos de fadas" en II Congresso Internacional de Leitura e Literatura Infantil e Juvenil, Mayo 2010, Portoalegre, Brasil.

WELLS, P.(1998) Understanding animation, Routledge, Londres

ZIPES, J. (2010) “On re-reading William Steig's Book Shrek!", http://www.tor.com/blogs/2010, Febrero 2010 (Última consulta febrero 2011) 